\title{
Homeopathy: scientific or not?
}

\author{
Beuy Joob \\ Viroj Wiwanitkit ${ }^{2,3}$
}

\begin{abstract}
1. Sanitation 1 Medical Academic Center, Bangkok, Thailand 2. Visiting professor, Hainan Medical University, Haikou, Hainan, China; 3. Honorary professor, Dr DY Patil University, DY Patil University, Pune, Maharashtra, India
\end{abstract}

\section{Dear Editor}

We read the publication on "Special Dossier: Scientific Evidence for Homeopathy" with great interest ${ }^{1}$ and would like to share ideas on this issue. In fact, homeopathy becomes an alternative medicine system that is presently used worldwide but there are several comments on its scientific reliability. It is usually mentioned that homeopathy's effect is a type of placebo effect ${ }^{2}$. Although there are many publications on homeopathy, the proof of scientific merit is still a controversial issue and some medical scientists point to the "hoax" problem in those homeopathy reports ${ }^{3}$. Regardless of its actual biological effect, if we consider homeopathy as a type of alternative medicine, it might at least psychologically support the patients. In addition, there are some new findings that homeopathy might be useful in preventive medicine as prevention of tropical epidemic disease such as dengue ${ }^{4}$. This becomes a new hope for several poor countries. In our experience in Thailand, a tropical country in Indochina, some local physicians already use the homeopathy technique for dengue prevention but there is much criticism from others. Regarding the present status of homeopathy, the important question is where this alternative medicine system should be set and how to improve the quality management system for this alternative medicine practice.

\section{REFERENCES}

1. Teixeira MZ. Special Dossier: "Scientific Evidence for Homeopathy". Rev Assoc Med Bras (1992). 2018 Feb;64(2):93-94.

2. Relton C. Implications of the 'placebo effect' for CAM research. Complement Ther Med. 2013 Apr;21(2):121-4.

3. Teixeira MZ. Proofs that Homeopathic Medicine Works: Dossier "Scientific Evidence for Homeopathy" (Revista de Homeopatia, São Paulo Homeopathic Medical Association). Homeopathy. 2018 Feb;107(1):45.

4. Mahesh S, Mahesh M, Vithoulkas G. Could Homeopathy Become An Alternative Therapy In Dengue Fever? An example Of 10 Case Studies. I Med Life. 2018 Jan-Mar;11(1):75-82. 